\title{
Peritonite bacteriana espontânea
}

\section{Spontaneous bacterial peritonitis}

\author{
Edna Strauss ${ }^{1}$ e Wanda Regina Caly ${ }^{1}$
}

\begin{abstract}
Resumo A peritonite bacteriana espontânea ocorre em 30\% dos cirróticos com ascite e, neste grupo, apresenta altas taxas de morbidade e mortalidade. Os fatores predisponentes incluem a diminuição da defesa imunológica encontrada no homem nas fases avançadas da cirrose, o supercrescimento da flora intestinal e a translocação bacteriana da luz dos intestinos aos linfonodos mesentéricos. As manifestações clínicas variam de graves a leves ou ausentes, sendo sempre necessária a análise do líquido ascítico. O diagnóstico de peritonite bacteriana espontânea se faz pela contagem de neutrófilos $>250 / \mathrm{mm}^{3}$ no líquido ascítico associado ou não ao crescimento de bactéria na cultura. As enterobactérias predominam como causa da infecção, sendo a Echerichia coli a bactéria mais freqüentemente isolada. O diagnóstico precoce e o tratamento adequado provocaram a queda das taxas de mortalidade nas duas últimas décadas. O uso endovenoso de cefalosporinas de terceira geração mostra-se eficaz em $70 \%$ a $95 \%$ dos casos. A recorrência de peritonite bacteriana espontânea é comum e pode ser prevenida com norfloxacina oral, de uso contínuo. O surgimento de resistência bacteriana tem estimulado a procura de novas opções para a profilaxia da peritonite bacteriana espontânea; os probióticos constituem nova abordagem promissora, mas que necessita melhor avaliação. Recomenda-se a profilaxia primária de curta duração aos cirróticos com ascite que apresentem episódio de hemorragia digestiva alta.
\end{abstract}

Palavras-chaves: Peritonite. Bactéria. Cirrose. Ascite. Cefalosporinas.

Abstract Spontaneous bacterial peritonitis occurs in $30 \%$ of patients with ascites due to cirrhosis leading to high morbidity and mortality rates. The pathogenesis of spontaneous bacterial peritonitis is related to altered host defenses observed in end-stage liver disease, overgrowth of microorganisms, and bacterial translocation from the intestinal lumen to mesenteric lymph nodes. Clinical manifestations vary from severe to slight or absent, demanding analysis of the ascitic fluid. The diagnosis is confirmed by a number of neutrophils over 250/ $\mathrm{mm}^{3}$ associated or not to bacterial growth in culture of an ascites sample. Enterobacteriae prevail and Escherichia coli has been the most frequent bacterium reported. Mortality rates decreased markedly in the last two decades due to early diagnosis and prompt antibiotic treatment. Third generation intravenous cephalosporins are effective in $70 \%$ to $95 \%$ of the cases. Recurrence of spontaneous bacterial peritonitis is common and can be prevented by the continuous use of oral norfloxacin. The development of bacterial resistance demands the search for new options in the prophylaxis of spontaneous bacterial peritonitis; probiotics are a promising new approach, but deserve further evaluation. Short-term antibiotic prophylaxis is recommended for patients with cirrhosis and ascites shortly after an acute episode of gastrointestinal bleeding.

Key-words: Peritonitis. Bacteria. Cirrhosis. Ascites. Cephalosporins.

A peritonite bacteriana espontânea (PBE) é uma das principais complicações que acomete pacientes cirróticos com ascite, com elevadas taxas de morbimortalidade ${ }^{12}$. Entende-se por PBE a infecção bacteriana do líquido ascítico, caracterizada pelo crescimento de uma bactéria associada a número aumentado de neutrófilos neste líquido (>250/mm3) na ausência de foco intra-abodminal de infecção ${ }^{45}$. Deve-se, portanto, estabelecer o diagnóstico diferencial com as peritonites secundárias, em que a cultura pode demonstrar o crescimento de duas ou mais bactérias.

A prevalência de PBE em pacientes cirróticos hospitalizados com ascite foi avaliada em estudos prospectivos e variou de 7 a $25 \%$, enquanto o conjunto de infecções bacterianas atinge prevalências de 15\% a $47 \%$. Por outro lado, no grupo controle de infecções hospitalares, em não-cirróticos, a taxa de infecção

1. Hospital de Clínicas da Universidade de São Paulo e Hemocentro - Fundação Pró-Sangue, São Paulo, SP.

Endereço para correspondência: Dra. Edna Strauss. Divisão de Anatomia Patológica. Av. Dr. Enéas de Carvalho Aguiar $155 / 10^{\circ}$ andar, 05403-000 São Paulo, SP

e-mail: edna.strauss@hcnet.usp.br

Recebido para publicação em 6/8/2003

Aceito em 20/8/2003 
varia em torno de $5 \%$ a $10 \%$. Os cirróticos descompensados, particularmente na classe $C$ da classificação de Child-Pugh, são mais propensos a desenvolver infecções do que os compensados. Outros fatores como icterícia, desnutrição e, principalmente, a hemorragia digestiva alta, predispõem ao desenvolvimento de PBE. E mais, a infecção do líquido ascítico propicia o surgimento de insuficiência renal, quer do tipo funcional e reversível, quer a verdadeira síndrome hepato-renal do tipo I, com sobrevida média de 15 dias $^{1}$. As taxas de mortalidade na PBE eram elevadas quando de sua caracterização clínica na década de 1970, com queda significativa já na década de 1990, devido tanto ao diagnóstico precoce como à eficácia do tratamento empírico (Fígura 1). Em estudo recente demonstramos que, ao longo das últimas décadas, as taxas de mortalidade permaneceram estáveis nas diferentes infecções bacterianas que acometem o cirrótico, com exceção apenas da PBE, que caiu de $67 \%$ para $37 \% 41$.

A PBE é considerada, pela maioria dos autores, a infecção mais comum observada em cirróticos, tendo sido a primeira infecção espontânea descrita, embora hoje sejam admitidas também a bacteriemia e o

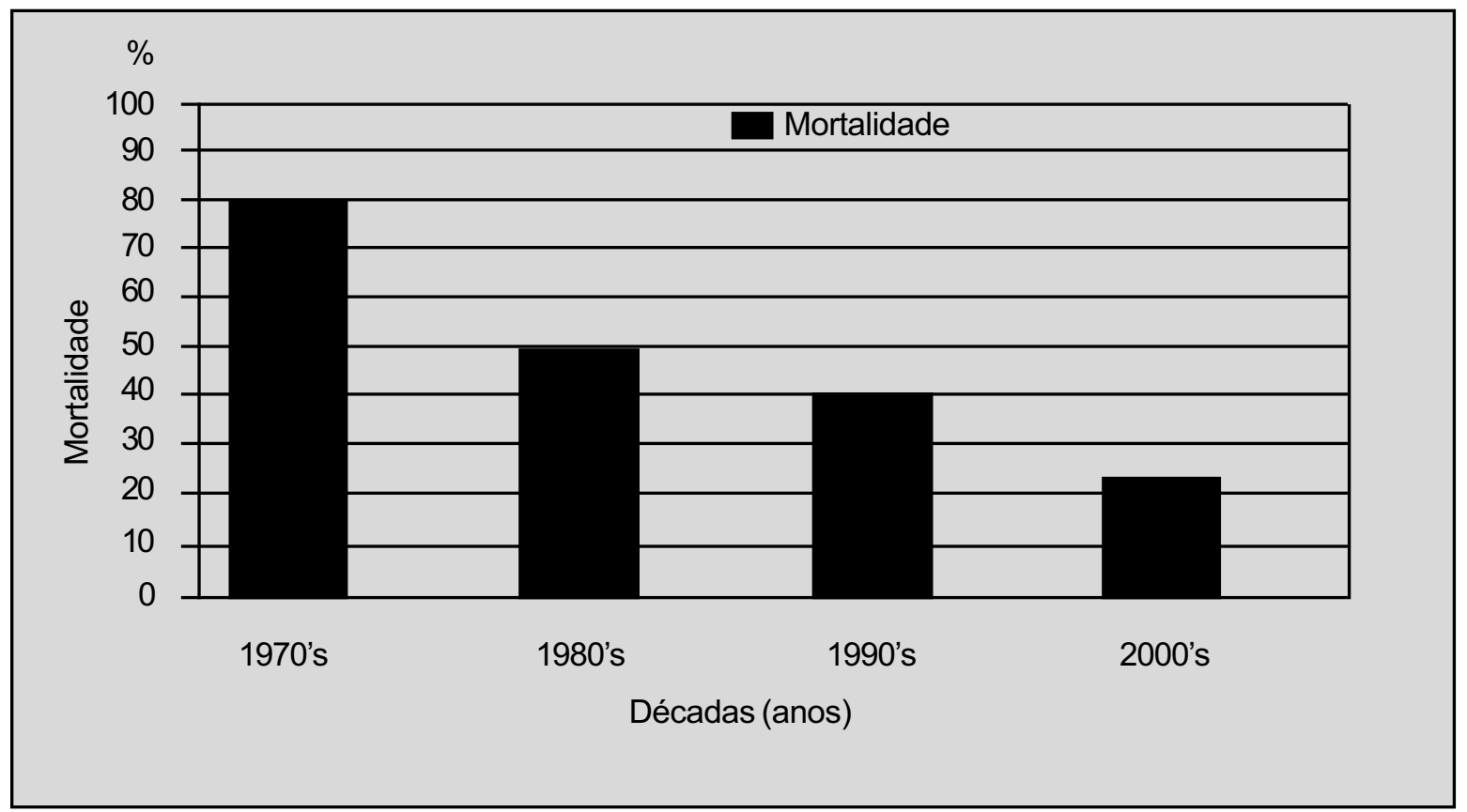

Figura 1 - Mortalidade de pacientes com cirrose e peritonite bacteriana espontânea em diferentes décadas.

empiema espontâneos ${ }^{18}$. Além da PBE, a infecção urinária, a pneumonia, as infecções de pele e tecido subcutâneo, bem como as septicemias, constituem o elenco mais freqüente de infecções bacterianas que surgem na evolução clínica da cirrose, ocasionando piora da função hepática e encurtando a sobrevida do paciente. Dentre elas, tanto a PBE, como a infecção urinária, destacam-se pela recorrência dos episódios infecciosos. De fato, estudos recentes demonstraram que no prazo de 12 meses, as probabilidades de novo episódio de PBE variaram de $47 \%$ a $69 \%{ }^{13} 43$.

Vários fatores são considerados como favorecedores da infecção na cirrose, entre eles citamos aqueles intrínsecos como as alterações da flora intestinal, do sistema macrófago-monocitário, da função dos neutrófilos bem como da imunidade humoral e celular. Entre os fatores circunstanciais incluem-se ainda o alcoolismo, a desnutrição, a hemorragia digestiva alta e a ruptura de barreiras naturais através da realização de exames invasivos, diagnósticos e terapêuticos, aos quais esses pacientes são freqüentemente submetidos ${ }^{12} 25$.

Os agentes bacterianos mais freqüentemente isolados na PBE são provenientes da flora intestinal, sendo constituídos por bactérias aeróbicas Gram negativas em cerca de $70 \%$ dos casos, o que torna os intestinos a mais provável fonte para as infecções espontâneas do cirrótico (Tabela 1). Questionou-se por muito tempo a passagem destas bactérias desde a luz intestinal até o líquido ascítico. Os conhecimentos sobre translocação bacteriana, definida como a passagem de bactérias viáveis da luz intestinal para sítios extraintestinais, vieram dos estudos realizados em pacientes em choque, com obstrução intestinal, endotoxemia, pancreatite aguda e, são atualmente plenamente aceitos como o mecanismo fisiopatogênico da $\mathrm{PBE}^{34}$. 
Tabela 1 - Bacterias isoladas (cultura) em grupo de cirróticos

\begin{tabular}{lrr} 
com infecções. & $\mathrm{N}$ & $\%$ \\
\hline Bacteria & & \\
\hline Aeróbicas gram-negativas & 12 & 25.53 \\
Enterobacteriaceae: & 4 & 8.51 \\
$\quad$ Escherichia coli & 5 & 14.89 \\
$\quad$ Klebsiella pneumoniae & 2 & 4.25 \\
$\quad$ Enterobacter cloacae & 3 & 6.39 \\
Enterobacter aglomerans & 1 & 2.13 \\
Proteus mirabilis & & \\
$\quad$ Morganella morganii & 1 & 2.13 \\
Outras gram-negativas: & 1 & 2.13 \\
$\quad$ Acinetobacter anitratus & & \\
Aeromonas sp. & & \\
Aeróbicas gram-positivas & & \\
Streptococcus: & & \\
$\quad$ Streptococcus do grupo D & 2 & 4.25 \\
$\quad$ não enterococcus & 5 & 10.64 \\
Streptococcus faecalis & 1 & 2.13 \\
Streptococcus pneumoniae & 2 & 4.25 \\
Streptococcus viridans & & \\
Staphylococcus: & & \\
$\quad$ Staphylococcus aureus & & \\
\hline Caly \& Strauss, 1993 & &
\end{tabular}

Estudos experimentais demonstraram a presença de bactérias intestinais viáveis nos linfonodos mesentéricos de ratos com cirrose ${ }^{14}$. A partir dos linfonodos elas alcançam o líquido ascítico, quer por via linfática quer por via hematológica, onde podem ou não ser destruídas pelas defesas naturais do organismo (Figura 2).

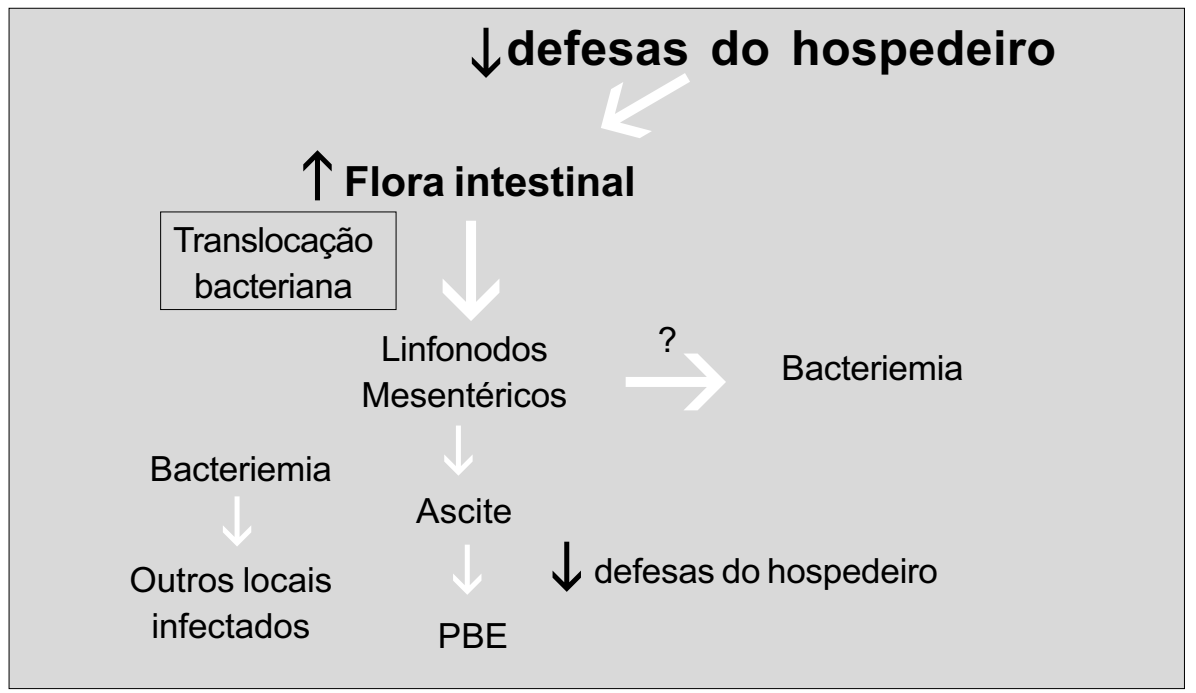

Figura 2 - Patogenia das infecções bacterianas espontâneas em cirróticos. $\mathrm{PBE}=$ peritonite bacteriana espontânea.

\section{DIAGNÓSTICO}

O diagnóstico da PBE pode ser clínico e/ou laboratorial. Clinicamente o paciente pode apresentar sintomas típicos como febre e dor à descompressão brusca do abdomen ou mesmo quadro compatível com infecção sistêmica grave, com choque séptico.
Entretanto, a ausência de sintomas típicos é relativamente freqüente, sendo importante a observação da piora repentina dos parâmetros de função renal ou surgimento de encefalopatia hepática, como formas veladas de manifestação inicial de PBE. 
Outras vezes faz-se o diagnóstico exclusivamente pelos exames laboratoriais, em formas clínicas totalmente assintomáticas ${ }^{8}$.

A avaliação laboratorial do líquido ascítico (LA) é a base fundamental para o diagnóstico da PBE, confirmado pelo encontro de $>250$ polimorfonucleares (PMN) por $\mathrm{mm}^{3}$ no LA, com ou sem isolamento bacteriano em sua cultura e/ou na hemocultura ${ }^{25} 31$. Ressalve-se que a técnica para obter melhores resultados de cultura exige a colocação do LA nos frascos de hemocultura para germes aeróbios logo após a punção, de preferência à beira do leito ${ }^{32}$.

Alguns estudos demostraram, entretanto, que mesmo utilizando-se esse método de coleta do LA, as culturas ainda se mostram negativas em aproximadamente 30 $50 \%$ dos pacientes que apresentam contagem $\geq 250$ $\mathrm{PMN}$ por $\mathrm{mm}^{3}$ no LA ${ }^{2023}$. Esta condição é conhecida como uma variante da $\mathrm{PBE}$, denominada de ascite neutrofilica cultura-negativa $(\mathrm{ANCN})^{28}$, que deverá receber a mesma conduta terapêutica destinada à $\mathrm{PBE}$ que tenha diagnóstico firmado pelo isolamento bacteriano, uma vez que seu curso evolutivo, freqüência de resolução e taxa de mortalidade são semelhantes ${ }^{25}$.

Outra variante da PBE é conhecida com o nome de bacterascite (BA), condição na qual isola-se uma bactéria no LA não sendo verificado aumento concomitante do número de PMN para mais de 250 por $\mathrm{mm}^{3}$. Esta variante deverá ser acompanhada clínica e laboratorialmente através de nova punção do LA, a ser realizada em intervalo de aproximadamente três dias, uma vez que representa uma colonização do LA, podendo se caracterizar como um estágio muito precoce da PBE ou ser reversível, principalmente nos casos assintomáticos ${ }^{1629}$. Na Tabela 2 resumem-se os achados diagnósticos na PBE e suas variantes, em contraste com as peritonites secundárias a processos inflamatórios intra-abdominais como colescistites, pancreatites, diverticulites e outros.

Nas infecções bacterianas dos cirróticos em geral, qualquer que seja a etiologia da cirrose, não se deve esperar pelos sinais ou sintomas clássicos de infecção para levantar esta hipótese diagnóstica. Em nossa experiência apenas $30 \%$ deles apresentam febre e a

Tabela 2 - Diagnóstico de peritonite bacteriana espontânea e suas variantes.

\begin{tabular}{lcccc}
\hline & PBE & AN & BA & PS \\
\hline Cultura de LA & $(+)$ & $(-)$ & $(+)$ & $(+)$ \\
PMN 250/mm3 & $(>)$ & $(>)$ & $(<)$ & $(>)$ \\
Infecção abdominal & $(-)$ & $(-)$ & $(-)$ & $(+)$
\end{tabular}

AN - ascite neutrofílica

A - liquido Ascítico

BA - bacteriascite

$\mathrm{PMN}$ - polimorfonucleares

PS - peritonite secundária

contagem de leucócitos costuma ser normal ou mesmo diminuída, particularmente em casos de PBE e infecção urinária, sendo pouco freqüente o aumento de formas jovens (desvio à esquerda) ${ }^{39} 40$. Este comportamento é justificado pela conhecida imunossupressão que caracteriza as fases mais avançadas da cirrose hepática.

Em conclusão, todos os cirróticos hospitalizados por ascite ou que a desenvolvem durante a internação após intercorrência clínica, devem ser submetidos rotineiramente à paracentese diagnóstica, mesmo que não apresentem qualquer evidência clínica sugestiva de $\mathrm{PBE}^{12}{ }^{31}$.

\section{TRATAMENTO}

A PBE deve ser considerada complicação grave no curso evolutivo da cirrose hepática devido a sua alta taxa de mortalidade, ainda em torno de $10-30 \%{ }^{612}$, muito embora bem menor do que quando de sua identificação clínica na década de $1970^{8}$. A importante diminuição nos percentuais de letalidade no decorrer dos últimos 20 anos deveu-se à melhoria dos métodos diagnósticos e à precocidade com que se inicia o tratamento ${ }^{25}$.

No tratamento da PBE iremos discorrer separadamente sobre: 1) tratamento do episódio infeccioso agudo; 2) prevenção da recorrência infecciosa; e 3) profilaxia primária da infecção.

Tratamento do episódio infeccioso agudo. Uma vez realizado o diagnóstico clínico e/ou laboratorial da PBE a antibióticoterapia deverá ser iniciada empiricamente, isto é, mesmo antes que o resultado de cultura do LA e/ou da hemocultura seja liberado pelo laboratório. A maioria das bactérias isoladas no LA e/ou hemocultura durante a PBE são aeróbias Gram negativas da família Enterobacteriaceae, sendo mais freqüêntes a Echerichia coli e o Streptococcus sp, não enterococo ${ }^{22}$. Desta forma, o tratamento inicial deverá ter espectro de inibição das bactérias mais comumente encontradas, com mínimos efeitos deletérios para o organismo, especialmente fígado e rins.

A partir do início dos anos 1980, várias foram as publicações acerca de resultados da terapia antibiótica para o tratamento da $\mathrm{PBE}^{74}$, verificando-se que as ampicilinas não apresentavam a eficácia esperada e as cefalosporinas de $1^{\text {a }}$ geração quando associadas aos aminoglicosídeos aumentavam o percentual de nefrotoxicidade ${ }^{4}$. Devido ao desenvolvimento de insuficiência renal com a utilização desses antibióticos, atualmente preconiza-se o uso das cefalosporinas de $3^{a}$ geração, por via endovenosa, como as drogas de primeira escolha no tratamento do episódio agudo da $\mathrm{PBE}^{10}{ }^{33}$. Vários esquemas posológicos foram utilizados, com variações de $4 \mathrm{~g}$ a $8 \mathrm{~g}$ nas 24 horas por tempo de 7 a 10 dias, com mínimo de 5 dias de tratamento ${ }^{26}{ }^{30}$. Nos ensaios clínicos controlados a eficácia deste esquema terapêutico tem variado de $85 \%$ a $95 \%$. Na prática clínica, quando do tratamento de pacientes não selecionados, verificamos resposta 
terapêutica eficaz em torno de $70 \%$ dos casos $^{5}$. A mudança do esquema terapêutico, a partir dos resultados de cultura do líquido ascítico ou sangue, se faz necessária principalmente quando o germe isolado for Gram+, sendo indicado fazer associações ou trocar o antibiótico de acordo com a sensibilidade do germe. Salientamos, ainda, que pacientes com PBE não complicada, isto é, na ausência de choque séptico, hemorragia digestiva alta, encefalopatia hepática, íleo ou dosagem de creatinina sérica maior que $3 \mathrm{mg} / \mathrm{dl}$, podem receber tratamento por via oral, utilizando-se ofloxacina na dose de $400 \mathrm{mg}$ a cada 12 horas $^{23}$ ou ciprofloxacina ${ }^{42}$.

Recentemente, verificou-se que o tratamento da PBE com cefalosporinas de $3^{\text {a }}$ geração associada à infusão de altas doses de albumina por via endovenosa $(1,5 \mathrm{~g} / \mathrm{kg})$ como expansor plasmático, proporcionava menor incidência de alterações renais $(10 \%)$ quando comparado ao tratamento isolado com a cefalosporina (33\%), e reduzia a taxa de mortalidade hospitalar de $29 \%$ para $10 \%{ }^{38}$. Este único trabalho da literatura precisa ser confirmado por outros grupos, sendo necessário avaliar se doses menores de albumina ou o uso de outros expansores plasmáticos seriam igualmente eficazes em prevenir insuficiência renal. Nosso grupo apresentou recentemente estudo retrospectivo, com controle histórico, no qual o uso de albumina humana na dose de $20 \mathrm{~g} /$ dia por 5 dias concomitante ao esquema terapêutico tradicional da PBE não ocasionou diminuição significativa nos índices de insuficiência renal ou mortalidade ${ }^{5}$.

Prevenção da recorrência infecciosa. A recorrência da PBE é comum nos pacientes cirróticos com ascite que sobrevivem ao primeiro episódio, verificando-se uma probabilidade de reinfecção de $40-70 \%$ em um ano ${ }^{35} 43$. Portanto, entende-se por profilaxia secundária de longo prazo a atitude terapêutica para evitar novos episódios de infecção do líquido ascítico no cirrótico, sendo observado que o uso de norfloxacina na dose de 400mg/ dia por via oral, continuadamente, diminui significativamente o percentual de recorrência no primeiro ano de $68 \%$ para $20 \%{ }^{226}$ não alterando, entretanto, a taxa de sobrevida ${ }^{43}$.

O uso contínuo da norfloxacina provoca a descontaminação intestinal seletiva, por inibir o crescimento das bactérias Gram negativas aeróbicas, não alterando significativamente o restante da flora aeróbica e anaeróbica intestinal ${ }^{1336}$. O antibiótico deverá ser administrado até o desaparecimento completo da ascite, realização do transplante hepático ou óbito ${ }^{12}$.

Esta atitude terapêutica, embora adotada em vários centros, não é universalmente aceita. Questiona-se o surgimento de germes resistentes ou menos habituais, os quais podem também provocar o desenvolvimento de PBE, sendo demonstrada a emergência de enterobactérias resistentes às quinolonas ${ }^{11}$. Neste sentido, estudam-se outras atitudes terapêuticas que possam, agindo sobre a flora intestinal, prevenir o surgimento de PBE.

Uma das possibilidades é o uso de probióticos. Sabese de longa data que além das bactérias patogênicas da microbiota existem cepas não patogênicas ou comensais, como o Lactobacillus johnsonii e Bifidobacterium lactis, que estão sendo utilizadas em substituição aos antibióticos em várias enfermidades. A administração dessas bactérias vivas provoca: a) inibição competitiva com as cepas patogênicas; b) melhor função de barreira da mucosa intestinal, ocasionando diminuição da translocação bacteriana; c) atuariam ainda diminuindo a produção de citocinas pró-inflamatórias, como o $\mathrm{TNF}^{21}{ }^{24}$. Embora promissora, muitas dúvidas persistem ainda quanto à eventual terapia com probióticos. Aguardam-se estudos clínicos que definam a melhor associação de bactérias, sua posologia, bem como a eficácia comparativa com o esquema tradicional.

Profilaxia primária da infecção. A prevenção do surgimento de PBE está indicada nos pacientes cirróticos com elevado risco de desenvolvimento de infecções bacterianas, como os que apresentam episódio agudo de hemorragia digestiva alta ${ }^{6639}$. A este grupo de pacientes preconiza-se a administração oral de norfloxacina na dose de $400 \mathrm{mg}(12 / 12 \mathrm{hs})$ ou ciprofloxacina (oral ou EV) na dose de 500mg a cada 12 horas, durante 7 dias $^{725}{ }^{37}$. A meta-análise de cinco ensaios clínicos demonstrou que a profilaxia primária de curta duração leva à diminuição da incidência de infecções bacterianas, incluindo PBE, e ainda aumenta a sobrevida ${ }^{3}$.

Outro grupo de pacientes que poderia beneficiarse de profilaxia primária são aqueles com dosagem da proteína total no LA em níveis inferiores a $1 \mathrm{~g} / \mathrm{dl}^{15} 19$. Sabe-se que o nível de proteínas do líquido ascítico possui relação direta com a atividade opsônica do LA, ou seja sua capacidade de impedir a colonização de germes e desenvolvimento de PBE, já que é freqüente a chegada de bactérias ao líquido ascítico. Dessa forma, aguarda-se novos ensaios clínicos, placebo-controlados, que possam validar a inclusão de pacientes com estas características na profilaxia primária da $\mathrm{PBE}^{12}$.

$\mathrm{Na}$ insuficiência hepática grave, por outro lado, a profilaxia primária de infecções bacterianas é mandatória ${ }^{27}$. Em artigo recente (em publicação) demonstramos que também na hepatite alcoólica grave, geralmente acompanhada de encefalopatia hepática, o pior prognóstico dos casos infectados sugere o uso profilático de antibióticos, para evitar entre outras infecções o surgimento de PBE. Afora estas condições, os dados atuais não justificam, até o momento, antibióticos profiláticos de longa duração em cirróticos não sangrantes e sem episódio prévio de $\mathrm{PBE}^{1225}$. Na Tabela 3 fornecemos os esquemas de tratamento usualmente empregados nas condições acima descritas. 
Tabela 3 - Esquemas de tratamento da peritonite bacteriana espontânea.

\begin{tabular}{lcc}
\hline & Clássico & Opcional \\
\hline Episódio agudo & Cefalosporina & Casos não complicados cipro ou ofloxacina \\
\hline Prevenção de recorrência & $3^{\text {a geração EV 2g 8/8h 7dias }}$ & 500 e 400mg 12/12h - 7 dias \\
\hline Profilaxia primária / HDA & norfloxacina 400mg/dia uso contínuo & Probióticos ?? \\
\hline HDA & norfloxacina 400mg12/12h - 7 dias & Ciprofloxacino oral ou EV
\end{tabular}

Concluindo, cumpre ressaltar que a expectativa de vida dos pacientes após um episódio de PBE gira em torno de $30-50 \%$ em um ano ${ }^{35} 43$ e existe significativo aumento dessa sobrevida após a realização do transplante hepático ${ }^{2}$. Assim, os pacientes que sobrevivem ao episódio de PBE tornam-se candidatos formais ao transplante hepático ${ }^{25}$.

\section{REFERÊNCIAS BIBLIOGRÁFICAS}

1. Arroyo V, Ginès P, Gerbes AL, Dudley FJ, Gentilini P, Laffig G, Reynolds TB, Ring-Larsen H, Scholmerich J. Definition and diagnosis criteria of refractory ascites and hepatorenal syndrome in cirrhosis. Hepatology 23:164-175, 1996.

2. Bac DJ. Spontaneous bacterial peritonitis: an indication for liver transplantation? Scandinavian Journal of Gastroenterolology 218 (suppl): 38-42, 1996

3. Bernard B, Grange JD, Khac EN, Amiot X, Opolon P, Poynard T. Antibiotic prophylaxis for the prevention of bacterial infections in cirrhotic patients with gastrointestinal bleeding: a metaanalysis. Hepatology 29:1655-1661, 1999.

4. Cabrera J, Arroyo V, Ballesta AM, Rimola A, Gual J, Elena M, Rodes J. Aminoglycosid nephrotoxicity in cirrhosis. Value of urinary $\beta_{2}$ microglobulin to discriminate functional renal failure from acute tubular damage. Gastroenterology 82: 97-105, 1982.

5. Caly WR, Morais EM, Alencar RSSM, Ribeiro MFGS, Chehter $E Z$, Strauss E. Infusão de albumina na prevenção de insuficiência renal durante terapia da peritonite bacteriana espontânea: estudo de caso-controle. In: Anais da V Semana Brasileira do Aparelho Digestivo, Rio de Janeiro p.51, 2002.

6. Caly WR, Strauss E. A prospective study of bacterial infections in patients with cirrhosis. Journal of Hepatology 18: 353-358, 1993.

7. Conn HO, Atterbury, CE. Cirrhosis. In: Schiff L., Schiff E (eds). Diseases of the liver. Philadelphia, J.B. Lippincott 20:725-864, 1987.

8. Conn HO, Fessel JM. Spontaneous bacterial peritonitis in cirrhosis: variations on a theme. Medicine 50: 161-97, 1971.

9. Correia JP, Conn HO. Spontaneous bacterial peritonitis in cirrhosis: endemic or epidemic? Medical Clinics of North America 59: 936-81, 1975.

10. Felisart J, Rimola A, Arroyo V, Perez Ayuso RM, Quintero E, Gines $\mathrm{P}$, Rodes $\mathrm{J}$. Cefotaxime is more effective than is ampicillintobramycin in cirrhotics with severe infections. Hepatology 5 : 457-62, 1985

11. Fernandez J, Navasa M, Gomez J, Colmenero J, Vila J, Arroyo V, Rodes J. - Bacterial infections in cirrhosis: epidemiological changes with invasive procedures and norfloxacin prophylaxis. Hepatology 35:140-148, 2002

12. Garcia-Tsao G. Current management of the complications of cirrhosis and portal hypertension: Variceal hemorrhage, ascites, and spontaneous bacterial peritonitis. Gastroenterology 120:726-748, 2001.
13. Ginés P, Rimola A, Planas R, Vargas V, Marco F, Almela M, Forne M, Miranda ML, Llach J, Salmeron JM, Esteve M, Marqués JM, Anta MTJ, Arroyo V, Rodés J. Norfloxacin prevents spontaneous bacterial peritonitis recurrence in cirrhosis: results of a double-blind, placebo controlled trial. Hepatology 12:71624, 1990.

14. Guarner C, Runyon BA, Young S, Heck M, Sheikh MY. - Intestinal bacterial overgrowth and bacterial translocation in cirrhotic rats with ascites. Journal of Hepatology 26:1372-1378, 1997.

15. Guarner C, Sola R, Soriano G, Andrew M, Novella MT, Vila MC, Sabat M, Coll S, Ortiz J, Gomes C, Balanzo J. Risk of a first community acquired spontaneous bacterial peritonitis in cirrhotics with low ascitic fluid protein levels. Gastroenterology 117: 414-419, 1999.

16. Hoefs JC, Runyon BA. Spontaneous bacterial peritonitis. Hepatology 2:399-407, 1982.

17. Hsieh WJ, Hseh WJ, Lin HC, Hwang SJ, How MC, Lee FY, Chang FY, Lee SD. The effect of ciprofloxacin in the prevention of bacterial infection in patients with cirrhosis after upper gastrointestinal bleeding. American Journal of Gastroenterology 93:962-965, 1998.

18. Kirchmair R, Allerberger F, Bangerl I, Egger C, Nachbaur K, Patsch JR, Vogel W. Spontaneous bacterial pleural empyema in liver cirrhosis. Digestive Disease and Science 43:1129-1132, 1998.

19. Llach J, Rimola A, Navasa M, Gines P, Salmeron JM, Gines A, Arroyo $\mathrm{V}$, Rodes $\mathrm{J}$. Incidence and predictive factors of first episode of spontaneous bacterial peritonitis in cirrhosis with ascitis: relevance of ascitic fluid protein concentration. Hepatology 16: 724-727, 1992.

20. Llovet JM, Planas R, Morillas R, Quer JC, Cabre E, Boix J, Humbert P, Guilera M, Domenech E, Bertran X, Gassull MA. Short-term prognosis of cirrhotics with spontaneous bacterial peritonitis: multivariate study. American Journal of Gastroenterology 88:388-92, 1992.

21. Madsen $K$, Cornihsh A, Soper $P$, McKaigney $C<$ Jijon $H$, Yachimec C, Doyle J, Jewell L, De Simone C. Probiotic bacteria enhance murine and human intestinal epithelial barrier function. Gastroenterology 121:580-591, 2001.

22. Mattos AA. Peritonite bacteriana espontânea e suas variantes. Tese de Livre - Docência. Fundação Faculdade Federal de Ciências Médicas de Porto Alegre, 1992. 
23. Navasa M, Follo A, Llovet JM, Clemente G, Vargas V, Rimola A, Marco F, Guarner C, Forne M, Planas R, Banares R, Castells L, Jimenez De Anta MT, Rodes J. Randomized, comparative study of oral ofloxacin versus intravenous cefotaxime in spontaneous bacterial peritonitis. Gastroenterology 111:10111017, 1996.

24. Resta-Lenert S, Barrett KE. Live probiotics protect intestinal epithelial cells from the effects of infection with enteroinvasive Escherichia coli (EIEC), Gut 52:988-997, 2003.

25. Rimola A, Garcia-Tsao G, Navasa M, Piddock LJ, Planas R, Bernard B, Inadomi JM. Diagnosis, treatment and prophylaxis of spontaneous bacterial peritonitis: a consensus document. Journal of Hepatology 32:142-153, 2000.

26. Rimola A, Salmeron JM, Clemente G, Rodrigo L, Obrador A, Miranda ML, Guarner C, Planas R, Sola R, Vargas V, Casafont F, Marco F, Navasa M, Banares R, Arroyo V, Rodes J. Two different dosages of cefotaxime in the treatment of spontaneous bacterial peritonitis in cirrhosis: results of a prospective, randomized, multicenter study. Hepatology 21:674-679, 1995.

27. Rolando N, Harvey F, Brahm J, Philpott-Howard J, Alexander G, Gimson A, Casewell M, Fagan E, Williams R. Prospective study of bacterial infection in acute liver failure: an analysis of fifty patients. Hepatology 11: 49-53, 1990.

28. Runyon BA. Culture-negative neutrocytic ascites: a variant of spontaneous bacterial peritonitis. Hepatology 4:1209-1211, 1984.

29. Runyon BA. Monomicrobial non-neutrocytic bacterascites: a variant of spontaneous bacterial peritonitis. Hepatology 12:710715, 1990.

30. Runyon BA, Akriviadis EA, Sattler FR, Cohen J. Ascitic fluid and serum cefotaxime and desacetyl cefotaxime levels in patients treated for bacterial peritonitis. Digestive Disease and Science 12:1782-1786, 1991.

31. Runyon BA, Antillon MR. Ascitic fluid $\mathrm{pH}$ and lactate: insensitive and nonspecific tests in detecting ascitic fluid infection. Hepatology 13: 929-935, 1991.

32. Runyon BA, Canawati HN, Akriviadis EA. Optimization of ascitic fluid culture technique. Gastroenterology 95: 1351-1355, 1988.

33. Runyon BA, Mc Hutchison JG, Antillon MR, Akriviadis EA, Montano AA. Short-course versus long course antibiotic treatment of spontaneous bacterial peritonitis. A randomized controlled study of 100 patients. Gastroenterology 100:17371742, 1991.
34. Runyon BA, Squiers S, Borzio M. - Translocation of gut bacteria in rats with cirrhosis to mesenteric lymph nodes partially explains the pathogenesis of spontaneous bacterial peritonitis. Journal of Hepatology 21:792-796, 1994.

35. Silvain C, Mannant R, Ingrand P, Fort E, Besson I, Beauchant $M$. Recidive de l'infection spontanée du liquide d'ascite au cours de la cirrhose. Gastroenterologie Clinique et Biologique15:106109, 1991.

36. Soriano G, Guarner C, Teixido M, Such J, Barrios J, Enriquez J, Villandell F. Selective intestinal decontamination prevents spontaneous bacterial peritonitis. Gastroenterology 100:477481, 1991.

37. Soriano G, Guarner C, Tomas A, Villanueva C, Torras X, Gonzalez D, Sainz S, Anguera A, Cusso X, Balanzo J, Vilardell F. Norfloxacin prevents bacterial infection in cirrhotics with gastrointestinal hemorrhage. Gastroenterology 103: 1267-1272, 1992.

38. Sort P, Navasa M, Arroyo V, Aldegner X, Planas R, Ruiz delArbol L, Castells L, Vargas V, Soriano G, Guevara M, Gines $P$, Rodes J. Effect of intravenous albumin on renal impairment and mortality in patients with cirrhosis and spontaneous bacterial peritonitis. New England Journal of Medicine 341:403-409, 1999.

39. Strauss E, Caly WR. Cirrose e Infecções Bacterianas. In: Gayotto LCC, Alves VAF (eds). Doenças do Fígado e Vias Biliares. Ed.Atheneu; 56:655-664, 2001.

40. Strauss E, Costa MF. The importance of bacterial infections as precipitating factors of chronic hepatic encephalopathy in cirrhosis. Hepato-Gastroenterology 45:900-904, 1998.

41. Strauss E, Ribeiro MFGS. Bacterial infections associated with hepatic encephalopathy: prevalence and outcome. Annals of Hepatology 2: 41-45, 2003.

42. Terg R, Cobas S, Fassio E, Landeira G, Rios B, Vasen W, Abecasis R, Rios H, Guevara M. Oral ciprofloxacin after a short course of intravenous ciprofloxacin in the treatment of spontaneous bacterial peritonitis: results of a multicenter, randomized study. Journal of Hepatology 33: 564-569, 2000.

43. Titó L, Rimola A, Ginés P, Llach J, Arroyo V, Rodés J. Recurrence of spontaneous bacterial peritonitis in cirrhosis: frequency and predictive factors. Hepatology 8:27-31, 1988.

44. Wilcox CM, Dismukes WE. Spontaneous bacterial peritonitis. A review of pathogenesis, diagnosis and treatment. Medicine 66: 447-456, 1987. 